\title{
Urine Ammonium Oxalate Crystal Measurement
}

National Cancer Institute

\section{Source}

National Cancer Institute. Urine Ammonium Oxalate Crystal Measurement. NCI

Thesaurus. Code C74759.

The determination of the amount of ammonium oxalate crystals present in a urine sample. 